\title{
Sleep, Immunological Memory, and Inflammatory Skin Disease
}

\author{
Bridget Myers Vidhatha Reddy Stephanie Chan Quinn Thibodeaux \\ Nicholas Brownstone Tina Bhutani \\ Department of Dermatology, University of California San Francisco, San Francisco, CA, USA
}

\section{Introduction}

Despite the well-known advantages of adequate sleep for the human body, the impact of sleep on chronic inflammatory skin disease is underappreciated [1]. Psoriasis, atopic dermatitis, hidradenitis suppurativa, and vitiligo patients experience a greater prevalence of sleep dysfunction versus the general population [2-5], which likely contributes to their reduced health-related and overall quality of life [6-9]. Sleep dysfunction in these patients may also have repercussions regarding the development and progression of their chronic inflammatory skin disease, and the systemic comorbidities associated with them. This may be, in part, explained by the bidirectional relationship between sleep and the immune system, which we discuss below.

\section{Impact of Sleep on the Immune System}

Recent research supports the influential role that sleep behavior is capable of having on immune function. For example, sleep dysfunction following vaccination is linked to decreased antibody response [10], and short sleep duration is shown to increase susceptibility to viral illness [11]. These outcomes may be in part related to the impact of sleep on immune memory formation. Slowwave sleep (SWS), which is considered the deepest type of sleep occurring during non-rapid eye movement (NREM) sleep, promotes the redistribution of antigenic information in antigen-presenting cells (APCs) to T cells for long-term storage. SWS creates an ideal environment for immune cell memory formation by increasing growth hormone and prolactin and decreasing catecholamine and cortisol levels. These conditions promote an increased number and efficiency of APC and CD4+ T-cell interactions, broader recruitment of $\mathrm{T}$-cell receptors on CD4+ T cells, and increased synthesis of pro-inflammatory cytokines, such as IL-17, which supports memory T-cell survival [12]. Sleep dysfunction could be disruptive to these neuroendocrine conditions, negatively effecting immune cell memory consolidation [13]. This may have some clinical relevance for the onset, maintenance, and progression of chronic inflammatory skin diseases, such as vitiligo and psoriasis, which are driven by aberrant memory T cells $[14,15]$.

Beyond its regulatory effect on immune cell memory formation, sleep has also been evidenced to affect the im- karger@karger.com

www.karger.com/drm

Karger $\stackrel{2}{\circ}$ (c) 2020 S. Karger AG, Base
Bridget Myers

515 Spruce Street

San Francisco, CA 94118 (USA)

bamyers@umich.edu 
mune system in other ways. Even just one night of sleep deprivation is seen to increase pro-inflammatory TNF- $\alpha$ concentration [16] and five days of sleep restriction can shift the Th1/Th2 ratio toward Th2, [17] potentially affecting Th2-mediated diseases such as atopic dermatitis. Future research would be helpful to assess whether the immunomodulatory effects of sleep impact the course of chronic inflammatory skin diseases. While disease severity is seen to correlate with poor sleep in psoriasis patients [18], it is unclear whether more severe disease leads to poor sleep or whether poor sleep leads to more severe disease, with both likely playing a role. The influence of sleep dysfunction on chronic inflammatory diseases has not yet been assessed in dermatology patients, but it has been explored in IBD patients. In murine models of colitis, chronic intermittent sleep deprivation was found to increase colonic inflammation and colitis severity [19], and in IBD patients, self-reported sleep quality demonstrated an inverse correlation with serum C-reactive protein levels [20].

\section{Impact of the Immune System on Sleep}

Sleep and the immune system are part of a bidirectional feedback loop. While sleep is suggested to have a regulatory effect on immune memory formation, immune system activity is conversely demonstrated to influence sleep parameters such as sleep latency, efficiency, and architecture. For instance, cytokines IL-1, TNF, IL-2, IL-4, IL-10, IL-13, IL-15 IL-16, and IL-18 have all been shown to harbor physiological sleep-modifying properties $[21,22]$. In animal studies, biologic inhibition of IL-1 and TNF have been shown to reduce NREM sleep, and elevation of IL-1 and TNF have been shown to increase NREM sleep and reduce rapid eye movement (REM) sleep. This suggests a role for IL-1 and TNF in maintaining a balance between NREM and REM sleep, which affects the amount of SWS an individual experiences [22]. Prostaglandins have also been shown to affect sleep architecture and SWS, with acute aspirin (an inhibitor of prostaglandin production) administration reducing sleep efficiency, increasing nighttime awakenings [23], and decreasing SWS in healthy adults [24].

The effects of chronic inflammation on sleep patterns have been explored in IBD and RA, with anti-TNF therapy leading to significant improvements in self-reported sleep quality in IBD [25] and RA patients [26, 27] and polysomnography-assessed sleep parameters in RA patients [28-30]. In one of these studies, TNF inhibitor therapy resulted in reduced sleep latency and increased sleep efficiency and REM sleep in RA patients independent of joint pain [29]. In another study, IL-6 inhibitor therapy in RA patients resulted in better self-reported sleep quality independent of disease activity [31]. The abundance and timing of IL- 6 and TNF accumulation have also been shown to influence sleep efficiency in RA patients [32], further suggesting an independent effect of cytokine levels on sleep behavior. This may be at play in linking hypertension and sleep dysfunction as well, as high blood pressure (which is associated with chronic inflammation) may be predictive of future insomnia in older adults [33].

In dermatology, we typically think of sleep disruption as a consequence rather than a cause of primary skin pathology, such as nocturnal pruritus in atopic dermatitis patients or pain with psoriatic arthritis in psoriasis patients. The increased prevalence of obesity, depression, and low quality of life in dermatology patients likely causes sleep dysfunction in this population as well. While the above studies suggest that an overactive immune system could be one of the factors contributing to sleep dysfunction in chronic inflammatory disease patients, future studies controlling for comorbid sleep-disturbing factors are necessary to determine the degree to which immune dysregulation alters sleep in dermatology patients. A useful population in which to study this could be vitiligo patients, as they exhibit an increased prevalence of sleepdisturbing parasomnias (sleep walking, nocturnal enuresis, night illusions, sleep terrors, and nightmares) [2], but do not characteristically suffer from pain or itch common to other skin diseases. Depression and low quality of life, common in vitiligo patients, would have to be accounted for.

\section{Sleep and Our Immune System in Skin Disease}

Given the relationship between sleep and the immune system and the robust correlation of sleep dysfunction with many skin diseases, sleep dysfunction could be contributing to chronic inflammation in certain skin diseases via its effect on immune memory. Memory $\mathrm{T}$ cells direct inflammation and autoimmunity and have been implicated in atopic dermatitis, contact dermatitis, vitiligo, and psoriasis, among others [34-36]. More recent evidence implicating tissue-resident memory $\mathrm{T}$ cells in vitiligo [37] and psoriasis [38] further supports the notion that many skin diseases are indeed "immune memory diseases" [32, $34,35]$.
Myers/Reddy/Chan/Thibodeaux/ Brownstone/Bhutani 
Sleep dysfunction is also strongly linked to several dermatologic comorbidities, especially cardiometabolic [39] and psychiatric disorders [40] in which chronic inflammation is implicated as well [41-43]. Individuals that get less than $5 \mathrm{~h}$ of sleep a night, on average, have a 2 - to 3 -fold greater risk of anxiety or depression compared to those who get $7 \mathrm{~h}$ of sleep a night [40]. Getting less than $5 \mathrm{~h}$ of sleep a night is further correlated with high BMI, obesity, diabetes, hypertension, hypercholesterolemia, heart attack, and stroke [39]. Notably, these comorbidities are associated with skin conditions that have a high prevalence of sleep dysfunction, such as atopic dermatitis [44], psoriasis [45], and hidradenitis suppurativa [46]. Poor sleep may play some role in driving the development of these comorbidities in dermatology patients, possibly through immune modulatory effects or others. In fact, psoriasis patients with a comorbid sleep disorder have been seen to have a higher risk of ischemic heart disease (HR 1.25, 95\% CI 1.22-1.28) and stroke (HR 1.24, 95\% CI 1.16-1.33) compared to psoriasis patients without a comorbid sleep disorder, supporting the role of sleep in augmenting the relationship between psoriasis and one of its major comorbidities, cardiovascular disease [47].

\section{Conclusion}

While understanding the effect of sleep on immune memory is preliminary, exploration of this relationship within the context of skin disease could lead to pathogenic and therapeutic insights. The repercussions of this may not only improve recognition of environmental conditions capable of triggering or maintaining aberrant or autoreactive T cells in skin disease, but may also help encourage dermatologists to emphasize sleep hygiene in their practice. The therapeutic potential of this may lead to improved management of one's skin disease as well as reduced risk of developing cardiometabolic and psychiatric comorbidities. This may help improve dermatology patients' quality of life and also reduce patients' morbidity and mortality, which is largely a consequence of cardiometabolic disease in psoriasis [48], hidradenitis suppurativa [49], and atopic dermatitis [50]. Potential modalities to be explored in future clinical trials include cognitive behavioral therapy and mindfulness exercises to manage sleep dysfunction in chronic inflammatory skin disease patients [51].

\section{Key Message}

Sleep affects immune memory, which plays an important role in many chronic inflammatory skin conditions.

\section{Conflict of Interest Statement}

The authors have no conflicts of interest to disclose.

\section{Funding Sources}

No funding sources were used for the purposes of this paper.

\section{Author Contributions}

T.B. and B.M were involved in generating and researching the commentary topic of interest. B.M. performed the literature search and drafted the manuscript. V.R., S.C., Q.T., and N.B. provided suggestions and edits to improve the manuscript.

\section{References}

1 Lo CM, Lee PH. Prevalence and impacts of poor sleep on quality of life and associated factors of good sleepers in a sample of older Chinese adults. Health Qual Life Outcomes. 2012 Jun;10(1):72.

2 Mouzas O, Angelopoulos N, Papaliagka M, Tsogas P. Increased frequency of self-reported parasomnias in patients suffering from vitiligo. Eur J Dermatol. 2008 Mar-Apr; 18(2): $165-8$.

3 Kaaz K, Szepietowski JC, Matusiak Ł. Influence of Itch and Pain on Sleep Quality in $\mathrm{Pa}$ tients with Hidradenitis Suppurativa. Acta Derm Venereol. 2018 Aug;98(8):757-61.
4 Gupta MA, Simpson FC, Gupta AK. Psoriasis and sleep disorders: A systematic review. Sleep Med Rev. 2016 Oct;29:63-75.

5 Chang YS, Chiang BL. Sleep disorders and atopic dermatitis: A 2-way street? J Allergy Clin Immunol. 2018 Oct;142(4):1033-40.

6 Bhosle MJ, Kulkarni A, Feldman SR, Balkrishnan R. Quality of life in patients with psoriasis. Health Qual Life Outcomes. 2006 Jun; $4(1): 35$.
7 Chernyshov PV, Zouboulis CC, Tomas-Aragones L, Jemec GB, Svensson A, Manolache L, et al. Quality of life measurement in hidradenitis suppurativa: position statement of the European Academy of Dermatology and Venereology task forces on Quality of Life and Patient-Oriented Outcomes and Acne, Rosacea and Hidradenitis Suppurativa. J Eur Acad Dermatol Venereol. 2019 Sep;33(9):1633-43.

8 Parsad D, Dogra S, Kanwar AJ. Quality of life in patients with vitiligo. Health Qual Life Outcomes. 2003 Oct;1(1):58

9 Lifschitz C. The impact of atopic dermatitis on quality of life. Ann Nutr Metab. 2015;66 Suppl 1:34-40.
Sleep, Immunological Memory, and Inflammatory Skin Disease 
10 Lange T, Dimitrov S, Bollinger T, Diekelmann S, Born J. Sleep after vaccination boosts immunological memory. J Immunol. 2011 Jul;187(1):283-90.

11 Prather AA, Janicki-Deverts D, Hall MH, Cohen S. Behaviorally Assessed Sleep and Susceptibility to the Common Cold. Sleep (Basel). 2015 Sep;38(9):1353-9.

12 Lange T, Born J, Westermann J. Sleep Matters: CD4+ T Cell Memory Formation and the Central Nervous System. Trends Immunol. 2019 Aug;40(8):674-86.

13 Westermann J, Lange T, Textor J, Born J. System consolidation during sleep - a common principle underlying psychological and immunological memory formation. Trends Neurosci. 2015 Oct;38(10):585-97.

14 Boniface K, Jacquemin C, Darrigade AS, Dessarthe B, Martins C, Boukhedouni N, et al. Vitiligo Skin Is Imprinted with Resident Memory CD8 T Cells Expressing CXCR3. J Invest Dermatol. 2018 Feb;138(2):355-64.

15 Casciano F, Pigatto PD, Secchiero P, Gambari R, Reali E. T Cell Hierarchy in the Pathogenesis of Psoriasis and Associated Cardiovascular Comorbidities. Front Immunol. 2018 Jun; 9:1390.

16 Chennaoui M, Sauvet F, Drogou C, Van Beers $\mathrm{P}$, Langrume C, Guillard M, et al. Effect of one night of sleep loss on changes in tumor necrosis factor alpha (TNF- $\alpha$ ) levels in healthy men. Cytokine. 2011 Nov;56(2):318-24.

17 Axelsson J, Rehman JU, Akerstedt T, Ekman R, Miller GE, Höglund CO, et al. Effects of sustained sleep restriction on mitogen-stimulated cytokines, chemokines and T helper 1/ $\mathrm{T}$ helper 2 balance in humans. PLoS One. 2013 Dec;8(12):e82291.

18 Smith MP, Ly K, Thibodeaux Q, Weerasinghe T, Beck K, Shankle L, et al. Factors Influencing Sleep Difficulty and Sleep Quantity in the Citizen Pscientist Psoriatic Cohort. Dermatol Ther (Heidelb). 2019 Sep;9(3):511-23.

19 Tang Y, Preuss F, Turek FW, Jakate S, Keshavarzian A. Sleep deprivation worsens inflammation and delays recovery in a mouse model of colitis. Sleep Med. 2009 Jun;10(6):597-603.

20 Wilson RG, Stevens BW, Guo AY, Russell CN, Thornton A, Cohen MA, et al. High CReactive Protein Is Associated with Poor Sleep Quality Independent of Nocturnal Symptoms in Patients with Inflammatory Bowel Disease. Dig Dis Sci. 2015 Jul;60(7): 2136-43.

21 Besedovsky L, Lange T, Haack M. The SleepImmune Crosstalk in Health and Disease. Physiol Rev. 2019 Jul;99(3):1325-80.

22 Opp MR. Cytokines and sleep. Sleep Med Rev. 2005 Oct;9(5):355-64.

23 Murphy PJ, Badia P, Myers BL, Boecker MR, Wright KP Jr. Nonsteroidal anti-inflammatory drugs affect normal sleep patterns in humans. Physiol Behav. 1994 Jun;55(6):1063-6.

24 Horne JA, Percival JE, Traynor JR. Aspirin and human sleep. Electroencephalogr Clin Neurophysiol. 1980 Aug;49(3-4):409-13.
25 Stevens BW, Borren NZ, Velonias G, Conway G, Cleland T, Andrews E, et al. Vedolizumab Therapy Is Associated with an Improvement in Sleep Quality and Mood in Inflammatory Bowel Diseases. Dig Dis Sci. 2017 Jan;62(1): 197-206.

26 Wolfe F, Michaud K, Li T. Sleep disturbance in patients with rheumatoid arthritis: evaluation by medical outcomes study and visual analog sleep scales. J Rheumatol. 2006 Oct; 33(10):1942-51.

27 Karatas G, Bal A, Yuceege M, Yalcin E, Firat $H$, Dulgeroglu D, et al. The evaluation of sleep quality and response to anti-tumor necrosis factor $\alpha$ therapy in rheumatoid arthritis patients. Clin Rheumatol. 2017 Jan;36(1):45-50.

28 Detert J, Dziurla R, Hoff P, Gaber T, Klaus P, Bastian $\mathrm{H}$, et al. Effects of treatment with etanercept versus methotrexate on sleep quality, fatigue and selected immune parameters in patients with active rheumatoid arthritis. Clin Exp Rheumatol. 2016 Sep-Oct;34(5): 848-56.

29 Zamarrón C, Maceiras F, Mera A, Gómez-Reino JJ. Effect of the first infliximab infusion on sleep and alertness in patients with active rheumatoid arthritis. Ann Rheum Dis. 2004 Jan;63(1):88-90.

30 Taylor-Gjevre RM, Gjevre JA, Nair BV, Skomro RP, Lim HJ. Improved Sleep Efficiency after Anti-Tumor Necrosis Factor $\alpha$ Therapy in Rheumatoid Arthritis Patients. Ther Adv Musculoskelet Dis. 2011 Oct;3(5):22733.

31 Fragiadaki K, Tektonidou MG, Konsta M, Chrousos GP, Sfikakis PP. Sleep disturbances and interleukin 6 receptor inhibition in rheumatoid arthritis. J Rheumatol. 2012 Jan;39(1): $60-2$.

32 Bjurström MF, Olmstead R, Irwin MR. Reciprocal Relationship Between Sleep Macrostructure and Evening and Morning Cellular Inflammation in Rheumatoid Arthritis. Psychosom Med. 2017 Jan;79(1):24-33.

33 Jarrin DC, Alvaro PK, Bouchard MA, Jarrin SD, Drake CL, Morin CM. Insomnia and hypertension: A systematic review. Sleep Med Rev. 2018 Oct;41:3-38.

34 Ferran M, Santamaria-Babi LF. Pathological mechanisms of skin homing $\mathrm{T}$ cells in atopic dermatitis. World Allergy Organ J. 2010 Mar; $3(3): 44-7$.

35 Santamaria Babi LF, Picker LJ, Perez Soler MT, Drzimalla K, Flohr P, Blaser K, et al. Circulating allergen-reactive $\mathrm{T}$ cells from patients with atopic dermatitis and allergic contact dermatitis express the skin-selective homing receptor, the cutaneous lymphocyteassociated antigen. J Exp Med. 1995 May; 181(5):1935-40.

36 Devarajan P, Chen Z. Autoimmune effector memory T cells: the bad and the good. Immunol Res. 2013 Dec;57(1-3):12-22.

37 Riding RL, Harris JE. The Role of Memory CD8+ T Cells in Vitiligo. J Immunol. 2019 Jul; 203(1):11-9.
38 Boyman O, Hefti HP, Conrad C, Nickoloff BJ, Suter M, Nestle FO. Spontaneous development of psoriasis in a new animal model shows an essential role for resident $\mathrm{T}$ cells and tumor necrosis factor-alpha. J Exp Med. 2004 Mar;199(5):731-6.

39 Altman NG, Izci-Balserak B, Schopfer E, Jackson N, Rattanaumpawan P, Gehrman PR, et al. Sleep duration versus sleep insufficiency as predictors of cardiometabolic health outcomes. Sleep Med. 2012 Dec;13(10):1261-70.

40 Geoffroy PA, Tebeka S, Blanco C, Dubertret C, Le Strat Y. Shorter and longer durations of sleep are associated with an increased twelvemonth prevalence of psychiatric and substance use disorders: findings from a nationally representative survey of US adults (NESARC-III). J Psychiatr Res. 2020 May; 124:34-41

41 Paragh G, Seres I, Harangi M, Fülöp P. Dynamic interplay between metabolic syndrome and immunity. Adv Exp Med Biol. 2014;824: 171-90.

42 Leonard BE. The concept of depression as a dysfunction of the immune system. Curr Immunol Rev. 2010 Aug;6(3):205-12.

43 Fernández-Ruiz I. Immune system and cardiovascular disease. Nat Rev Cardiol. 2016 Aug;13(9):503-503.

44 Paller A, Jaworski JC, Simpson EL, Boguniewicz M, Russell JJ, Block JK, et al. Major Comorbidities of Atopic Dermatitis: Beyond Allergic Disorders. Am J Clin Dermatol. 2018 Dec;19(6):821-38.

45 Oliveira MF, Rocha BO, Duarte GV. Psoriasis: classical and emerging comorbidities. An Bras Dermatol. 2015 Jan-Feb;90(1):9-20.

46 Porter ML, Kimball AB. Comorbidities of hidradenitis suppurativa. Semin Cutan Med Surg. 2017 Jun;36(2):55-7.

47 Chiu HY, Hsieh CF, Chiang YT, Tsai YW, Huang WF, Li CY, et al. Concomitant Sleep Disorders Significantly Increase the Risk of Cardiovascular Disease in Patients with Psoriasis [Internet]. PLoS One. 2016 Jan; 11(1):e0146462. [cited $2020 \mathrm{Feb} 22$ ] Available from: https://www.ncbi.nlm.nih.gov/pmc/articles/PMC4712908/

48 Abuabara K, Azfar RS, Shin DB, Neimann AL, Troxel AB, Gelfand JM. Cause-specific mortality in patients with severe psoriasis: a population-based cohort study in the U.K. Br J Dermatol. 2010 Sep;163(3):586-92.

49 Tiri H, Jokelainen J, Timonen M, Tasanen K, Huilaja L. Substantially reduced life expectancy in patients with hidradenitis suppurativa: a Finnish nationwide registry study. Br J Dermatol. 2019 Jun;180(6):1543-4.

50 Thyssen JP, Skov L, Egeberg A. Cause-specific mortality in adults with atopic dermatitis. J Am Acad Dermatol. 2018 Mar;78(3):506-10.

51 Magin P. Psoriasis and sleep: unravelling the relationship. Br J Dermatol. 2019 Jun;180(6): 1289-90. 